\title{
Effects of a purified krill oil phospholipid rich in long-chain omega-3 fatty acids on cardiovascular disease risk factors in non- human primates with naturally occurring diabetes type- 2 and dyslipidemia
}

\author{
Petter-Arnt Hals ${ }^{1 *}$, Xiaoli Wang ${ }^{2}$ and Yong-Fu Xiao ${ }^{2}$
}

\begin{abstract}
Background: High serum levels of cholesterol, in particular low-density lipoprotein cholesterol, are considered a significant risk factor for development of cardiovascular disease. Therefore, rigorous treatment regimens with statins and other pharmaceuticals have been used extensively to reduce elevated cholesterol levels. Literature data have not clearly concluded whether long-chain omega-3 fatty acids reduce, increase or leave circulating cholesterol unaffected. In the present study a novel krill-oil derived preparation of omega-3 rich phospholipids, mainly phosphatidylcholine, was administered orally at increasing doses for 12 weeks to dyslipidemic non-human primates, and cholesterols and several other risk factors for cardiovascular disease were measured before, during and after treatment.
\end{abstract}

Methods: Six dyslipidemic non-human primates suffering from naturally occurring diabetes type-2 were included, three in a vehicle control group and three being treated with the omega-3 rich phospholipid preparation. The control and test items were given daily by gavage and the doses of the test item were 50, 150 and $450 \mathrm{mg}$ phospholipids $/ \mathrm{kg} /$ day. Each dose level was given for 4 weeks. Plasma concentrations of the omega-3 fatty acids were measured in connection with change in dose and the omega-3 index in erythrocytes was determined biweekly. Blood lipids, apolipoproteins and diabetes, inflammatory and safety biomarkers were determined either weekly, biweekly or every 4 weeks. For the blood lipids and apolipoproteins, control-adjusted mean values are presented while absolute values are presented for the other parameters. Due to the low number of animals in each group, no statistical analyses were done.

Results: The only detectable effects measured during dosing with the lowest dose were an increase in HDLcholesterol and apolipoprotein A1. The intermediate and high doses decreased total cholesterol, LDL-cholesterol, apolipoprotein B100 and triglycerides and increased HDL-cholesterol and apolipoprotein A1. No effects were seen on the diabetes and inflammatory markers and on safety biomarkers.

Conclusions: The results indicate that the omega-3 rich phospholipid preparation had a positive impact on cardiovascular disease risk factors by reducing total cholesterol, LDL-cholesterol and triglycerides and increasing $\mathrm{HDL}$-cholesterol. These findings justify further investigations of this preparation in animal models of dyslipidemia and, provided the current findings are confirmed, in human trials.

Keywords: Phospholipids, Omega-3 fatty acids, Choline, Cholesterol, Cardiovascular disease

\footnotetext{
* Correspondence: petter-arnt.hals@akerbiomarine.com

${ }^{1}$ Aker Biomarine Antarctic AS, Oksenoyveien 10, N-1366 Lysaker, Norway

Full list of author information is available at the end of the article
} 


\section{Background}

Cholesterol is a natural component of mammalian cell membranes and is essential in this lipophilic barrier between cells. Lipoprotein complexes, which are composed of lipids and apolipoproteins, are required to transport cholesterol and lipids through the bloodstream. This transport system is crucial for life, but excessive concentrations of cholesterol in blood, especially when carried by low-density lipoproteins (LDLs) or very low density lipoproteins (VLDLs), can accumulate on the walls of arteries. These accumulated lipoproteins increase the risk for several cardiovascular diseases like stroke and ischemic heart disease including myocardial infarction, one leading cause of death in Western industrial societies. Hence, rigorous treatment regimens are often prescribed for patients diagnosed with elevated blood levels of cholesterols and in particular in the cases where LDL cholesterol (LDL-C) is above what is considered normal levels. For the last decades, inhibitors of the enzyme 3hydroxy 3-methylglutaryl Coenzyme-A reductase (HMG $\mathrm{CoA}$ ) have been the major treatment for the reduction of elevated cholesterol levels. These drugs, known as statins, inhibit HMG CoA and thereby one specific step in the cascade of cholesterol synthesis in cells and have proven clinically useful in the prevention of cardiovascular disease caused by hypercholesterolemia [1]. Recently, more novel drugs for reduction of circulating cholesterol, the proprotein convertase subtilisin/kexin type 9 (PCSK9) inhibitors, have been approved for clinical use. These new drugs act by reducing the endogenous production of PCSK9, which normally binds to the LDL receptor on hepatocytes and causes its internalization and lysosomal degradation, resulting in lower cellular concentrations of the LDL receptor and consequently a higher level of circulating LDL [2]. Other novel therapies for normalization of abnormal levels of circulating cholesterols include cholesteryl ester transfer protein (CETP) inhibitors like dalcetrapib [3], microsomal triglyceride transfer protein (MTP) inhibitors like lomitapide [4] and antisense therapy of which mipomersen is an FDA-approved drug [5].

Long-chain (LC) omega-3 fatty acids, in particular eicosapentaenoic acid (EPA; C20:5n3) and docosahexaenoic acid (DHA; C22:6n3), have long been assumed to have beneficial effects on cardiovascular health. Multiple biological effects known to be involved in the development of cardiovascular disease have been reported for these fatty acids, including reduction of blood triglycerides [6], improving endothelial function and reducing arterial wall stiffness $[7,8]$, reducing inflammations $[9,10]$, being antiarrhythmic [11], reducing blood pressure [12-14] and reducing overall risk for sudden cardiac death [15]. These two fatty acids are found only in marine sources like fat fish (e.g., salmon, mackerel and anchovies), krill and algae, and have been marketed for years as dietary supplements and more recently also as pharmaceutical products. The first approved pharmaceutical containing EPA and DHA was Omacor (generic name: omega-3-acid ethyl esters), also marketed by the name Lovaza, which is a preparation of EPA and DHA as ethyl esters [16]. The FDA-approved indication for this product is the reduction of triglycerides in patients having "very high" ( $>500 \mathrm{mg} / \mathrm{dL}$ ) plasma triglyceride levels [17]. Following the approval of Omacor/ Lovaza, several omega-3 products have been invented for this indication and are either on the market or under development.

LC omega-3 fatty acids occur naturally in fish oil mostly in the form of triglycerides. An alternative form of omega$3 \mathrm{~s}$ found in nature is as phospholipids, for which a major source is Antarctic krill (Euphausia suberba), an abundant krill species found in the Southern ocean. The main phospholipid in krill oil is phosphatidylcholine [18], an important source of the nutrient choline which since the 1930s has been known to have effects on how lipids, including cholesterol, are handled by the body [19]. Choline is oxidized to betaine, a methyl donor involved in the metabolism of homocysteine which at elevated concentrations has been associated with an increased risk of cardiovascular disease [20]. Therefore, phosphatidylcholine with a high content of omega- 3 fatty acids may provide several components that potentially can have a positive impact on risk factors for developing cardiovascular disease.

There have been conflicting data as to whether LComega- 3 fatty acids reduce, increase or leave circulating cholesterols unaffected. Early studies indicated clear and beneficial effects of these fatty acids, for example Illingworth et al. showed a significant decrease of both total cholesterol and LDL-c in healthy volunteers fed fish oil as compared to controls. However, in this study a very high LC omega-3 dose of $24 \mathrm{~g} /$ day was used [21]. More recent studies, applying lower omega-3 doses, have not been able to demonstrate similar effects on circulating cholesterols and for Omacor/Lovaza it has been published that in parallel with its triglyceride-reducing effect, a slight increase in LDL-c and high-density lipoprotein cholesterol (HDL-c) levels is observed [16, 22]. The general consensus in the literature seems to be that use of moderate doses of EPA and DHA, i.e., in the range of $0.5-5 \mathrm{~g} /$ day, does not reduce LDL-c concentrations in blood, a conclusion also reached by an Evidence-based Practice Center program under contract to the Agency for Healthcare Research and Quality (AHRQ), US Department of Health and Human Services in a report issued already back in 2004 [23] and updated recently with the same conclusion [24]. However, a remaining issue with the published data on LC omega$3 \mathrm{~s}$ and cholesterols is that important factors like dose 
levels, duration of treatment, type of omega-3 preparations used, EPA/DHA ratio in the dosed products, baseline cholesterol levels, diet, age and health status of the subjects as well as compliance with the planned dosing regimens vary considerably. It is therefore difficult to conclude uniformly on what effects an optimal and wellcontrolled use of an optimal preparation of omega-3 fatty acids could have on cholesterol levels in the most relevant patient population, i.e., in patients with pathologically elevated levels and thus having a significant risk of developing cardiovascular disease.

The primary objective of the study presented here was to undertake a first investigation of the long-term effects of a novel and highly purified phospholipid preparation rich in EPA and DHA, as well as choline, on blood levels of total cholesterol, LDL-c, HDL-c and triglycerides in dyslipidemic animals. The phospholipids in the preparation used in the study were extracted from krill oil. The animal model chosen for the study were cynomolgus monkeys with naturally occurring diabetes type- 2 which, as a result of the disease, also had elevated blood lipids. The model is described in detail in [25] and has shown to be a relevant model for human disease also in other aspects of diabetes, like for the development of left ventricular systolic and diastolic dysfunction frequently seen in diabetic patients [26]. As secondary objectives, we also investigated if the preparation had effects on diabetes markers and markers of inflammation. The safety of the product was assessed by measuring liver, kidney and coagulation biomarkers. Plasma and erythrocyte levels of EPA and DHA were monitored at multiple occasions during treatment.

The data reported in this article originate from a study which also analyzed the effects of the phospholipid preparation on the time course of erythrocyte membrane levels of 24 different fatty acids and the time course in plasma of 6 endocannabinoid-type compounds being downstream metabolites of some of the fatty acids analyzed in the erythrocytes. The results of these analyses will be published separately.

\section{Results}

\section{Plasma concentrations of EPA, DHA and DPA}

Plasma samples analyzed for EPA and DHA showed that the concentration of these fatty acids increased with increasing dose (Fig. 1, panels a and b). The mean baseline concentrations of EPA and DHA in the treated group were 332 and $4843 \mathrm{ng} / \mathrm{ml}$, respectively. After 4 weeks of treatment with the low dose of $50 \mathrm{mg} / \mathrm{kg} /$ day and just prior to the increase to the intermediate dose the mean plasma concentrations had increased to 2233 and $11477 \mathrm{ng} / \mathrm{ml}$. Following completion of treatment with the intermediate dose of $150 \mathrm{mg} / \mathrm{kg} /$ day the mean plasma concentrations were 6727 and $22400 \mathrm{ng} / \mathrm{ml}$, respectively, and at the end of the treatment with $450 \mathrm{mg} / \mathrm{kg} /$ day the concentrations were 12767 and $20867 \mathrm{ng} / \mathrm{ml}$, respectively. At the end of the 8-week wash-out period, the EPA and DHA plasma concentrations were 2693 and $12627 \mathrm{ng} / \mathrm{ml}$, respectively. For DPA, which might be considered a metabolite of EPA, the mean plasma concentration in the treated group was $444 \mathrm{ng} / \mathrm{ml}$ at baseline, $843 \mathrm{ng} / \mathrm{ml}$ at the end of the low dose treatment, 2277 at the end of the intermediate dose treatment, $2237 \mathrm{ng} / \mathrm{ml}$ at the end of the high dose treatment and $1196 \mathrm{ng} / \mathrm{ml}$ at the end of the wash-out period (Fig. 1, panel c). In the control group there was no change in the EPA concentration while an apparent, slight increase in DPA and DHA concentrations was noted during treatment, in particular during the period the highest dose was given (Fig. 1, panels a-c).

\section{Omega-3 index}

The relative amount in percent of $\mathrm{EPA}+\mathrm{DHA}$ in erythrocyte membranes as compared to the total amount of fatty acids in the membrane, the so-called omega-3 index [27], increased dose-dependently during the treatment period while no noticeable changes were observed in the control group (Fig. 1, panel d). At baseline the index was generally around 5-6\% except for one animal which had an index of $11.2 \%$. The mean baseline omega3 index in the control group was $6.0 \%$ and in the treated group $7.1 \%$. The lowest dose, $50 \mathrm{mg} / \mathrm{kg} /$ day, increased the index to a mean of $9.2 \%$ during the 4 weeks of dosing, the intermediate dose $(150 \mathrm{mg} / \mathrm{kg})$ increased it further to $13.1 \%$ and the highest dose $(450 \mathrm{mg} / \mathrm{kg} /$ day $)$ to $18.3 \%$ at the end of the 12 -week dosing. Following cessation of dosing the index declined and after 8 weeks without treatment the mean omega-3 index was $8.8 \%$. Interestingly, this rate of increase and decline is consistent with both EPA and DHA having standard first-order elimination kinetics.

Further details of the time course of the concentration of EPA, DHA and 22 other fatty acids in the erythrocytes during and after treatment will be published separately.

\section{Blood lipids and apolipoproteins}

The results for the primary parameters, the blood lipids and the apolipoproteins, are presented in Table 1. The concentrations of LDL were assessed in three different ways; LDL-c by the selective-chemically clearing method, total LDL particles by nuclear magnetic resonance (NMR) spectroscopy and ApoB100 by immune turbidimetry. Concentrations of HDL were assessed in four different ways; HDL-c by the polymer/detergent method and by NMR spectroscopy, total HDL particles by NMR spectroscopy and ApoA1 by immune turbidimetry. 


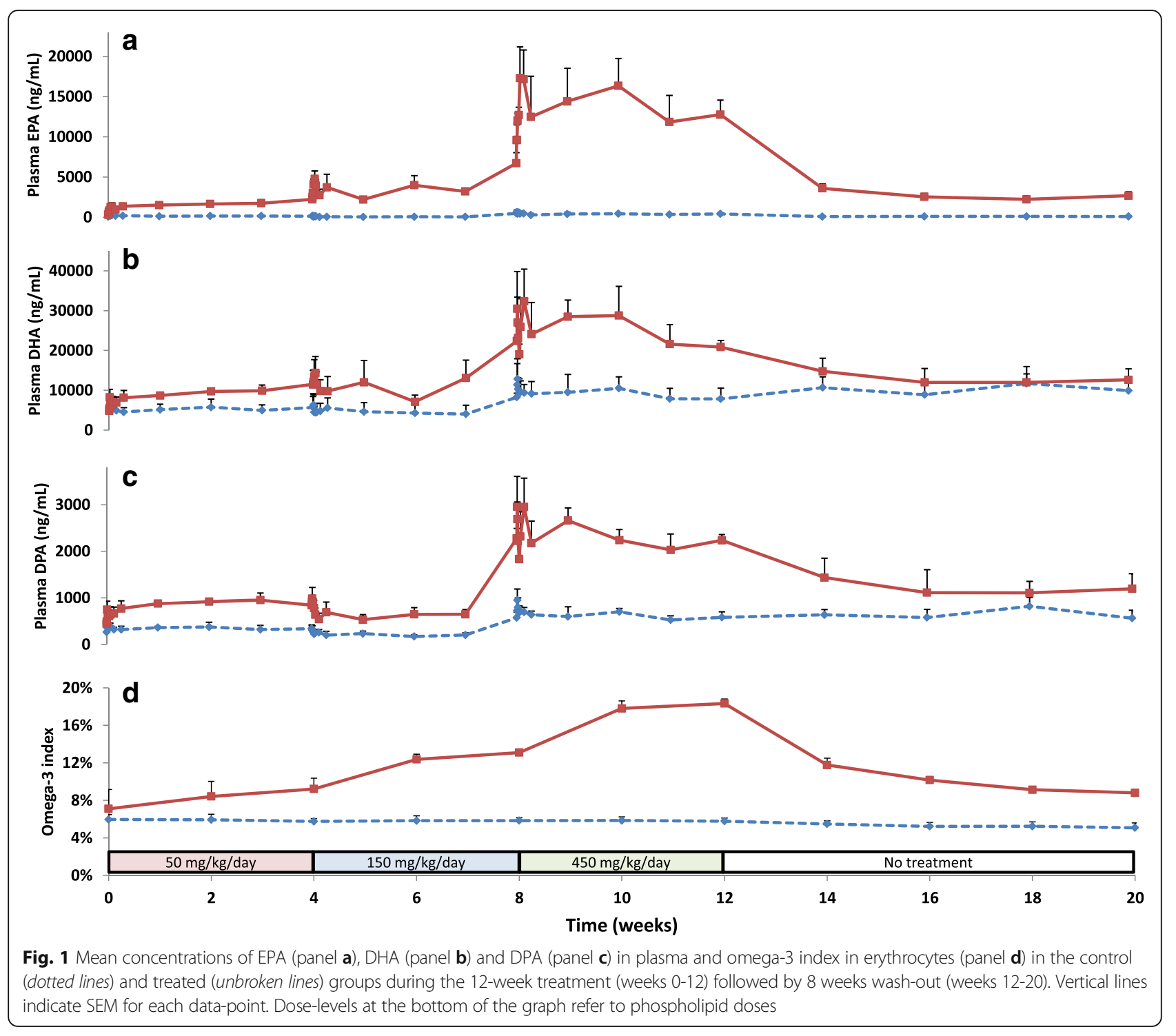

There was a marked variation in baseline values among the animals but for most of the primary parameters, higher-than-normal values were measured at start of treatment. The control-corrected values for the primary parameters are presented graphically in Fig. 2 and show that when treated with the intermediate and high dose levels of the phospholipid preparation, i.e., 150 and $450 \mathrm{mg} / \mathrm{kg} /$ day, total cholesterol, non-HDL cholesterol and LDL-c were dose-dependently reduced. In parallel to the reduction of LDL-c and LDL particles a reduction of ApoB100, the main apolipoprotein in LDL [28, 29], was observed. HDL-c and HDL particles, on the other hand, were increased during treatment. ApoA1, the principal apolipoprotein in HDL [30, 31], also increased although not to the same extent as HDL-c. The size of the LDL and HDL particles did not change as a result of treatment with the omega-3 rich phospholipid (Fig. 3).
After cessation of treatment in week 12, both total cholesterol and LDL-c concentrations increased towards the pre-dose levels, while HDL-c concentrations decreased towards the pre-dose level. This rebound effect further indicates that the changes in the cholesterols are significant effects which are reversible after stopping the treatment and, thus, directly linked to the administration of the study preparation and the coherent changes in the omega-3 index. Plasma triglycerides were markedly reduced by treatment, most significantly after the highest dose of $450 \mathrm{mg} / \mathrm{kg} /$ day. Treatment did not seem to consistently affect the levels of apolipoproteins ApoB48 or ApoE, however the levels of ApoC3, an important apolipoprotein in VLDL $[32,33]$, was reduced during the treatment period although not in a dose-related manner (Table 2). These three apolipoproteins were not followed during the wash-out period after cessation of treatment. 


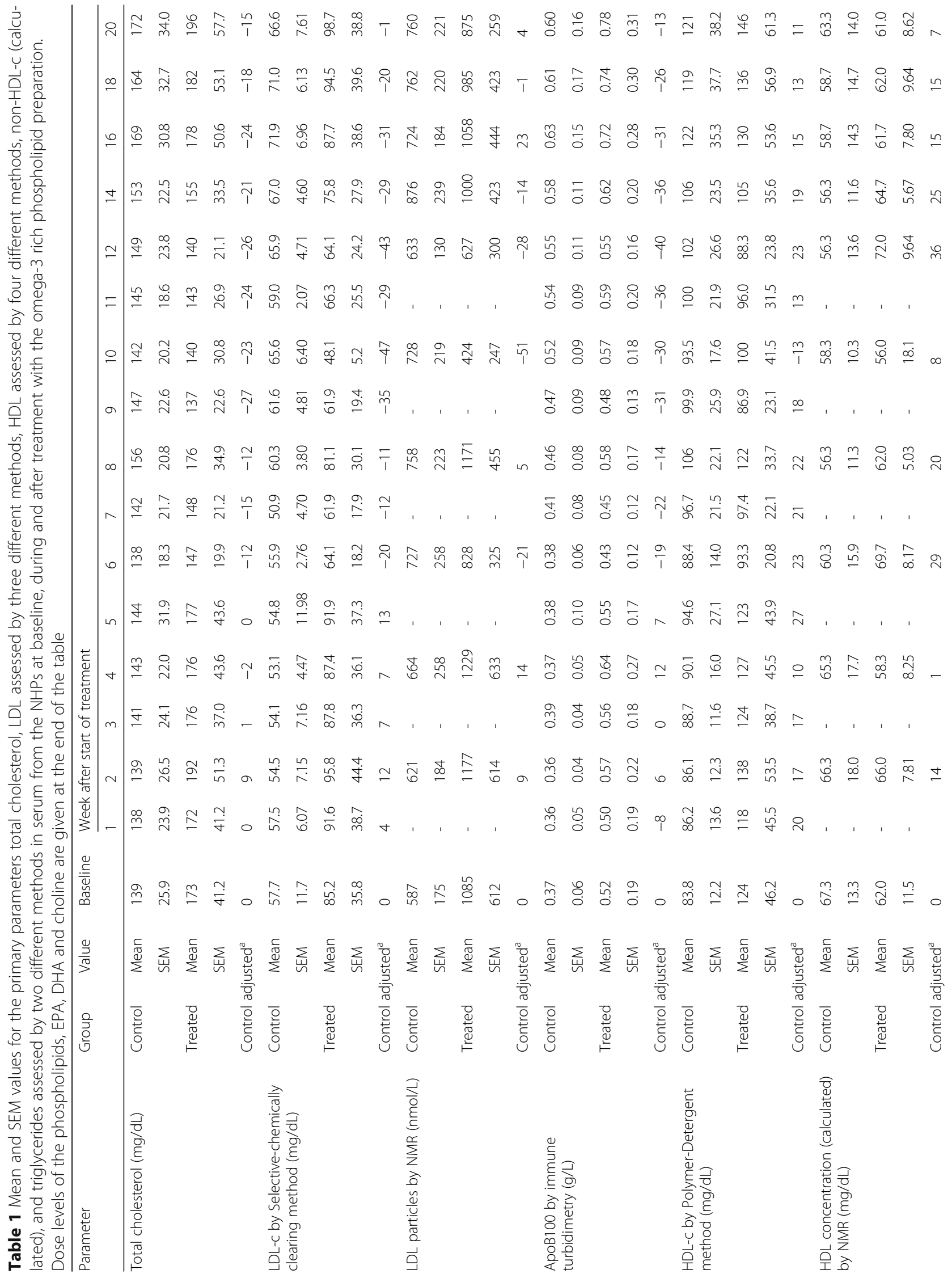




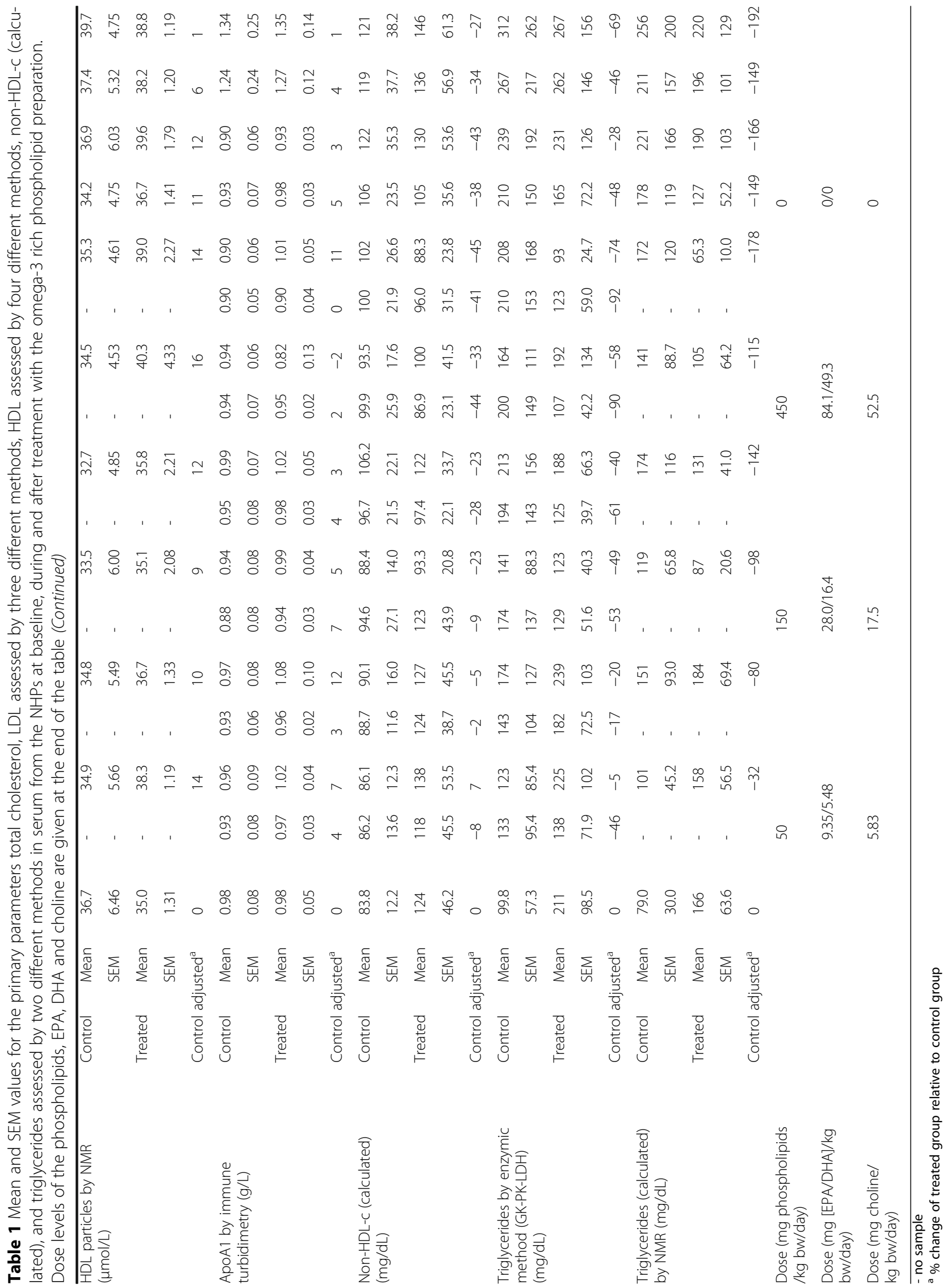



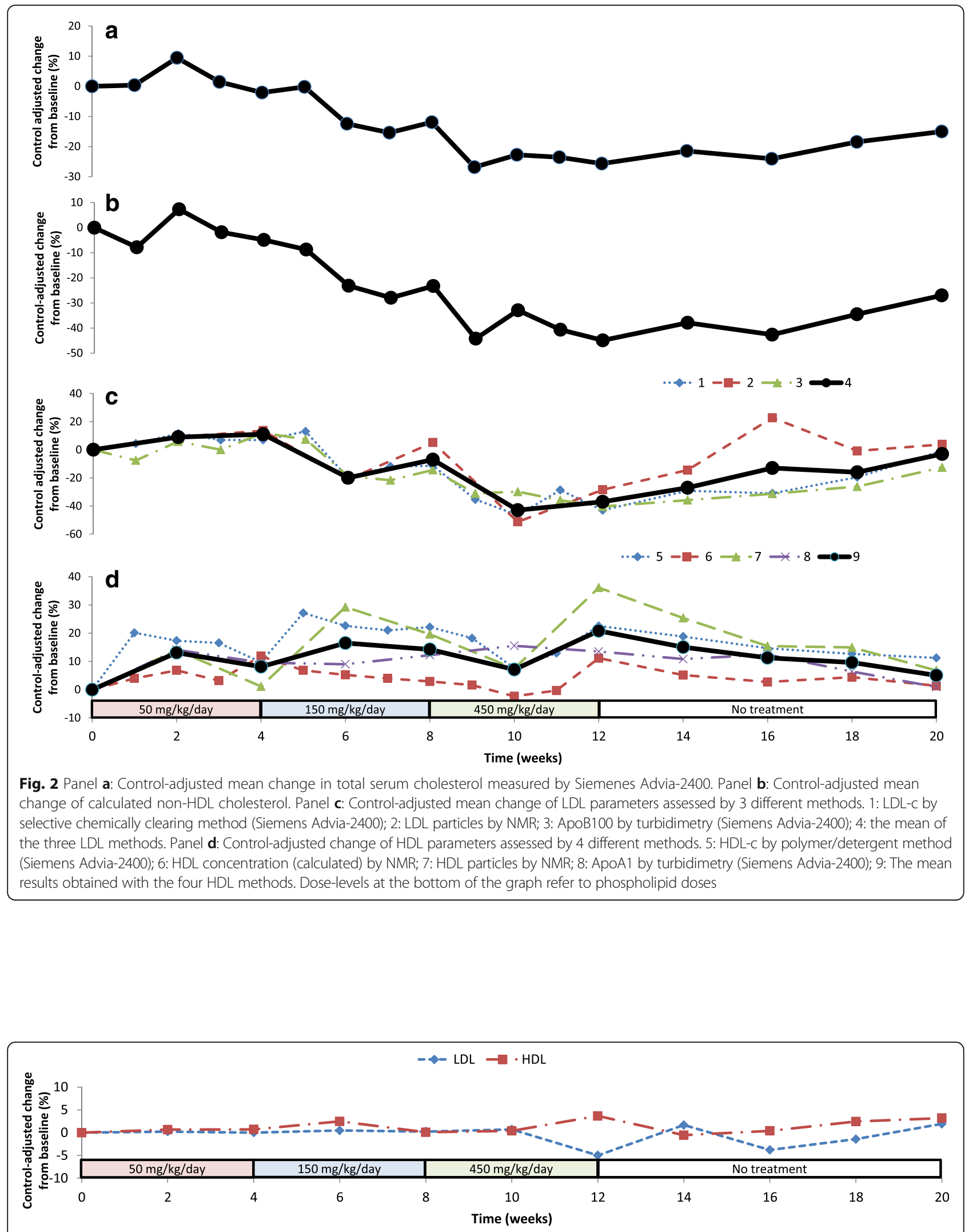

Fig. 3 Control adjusted mean values for \% change of LDL (unbroken line) and HDL (dotted line) particle size. Dose-levels at the bottom of the graph refer to phospholipid doses 


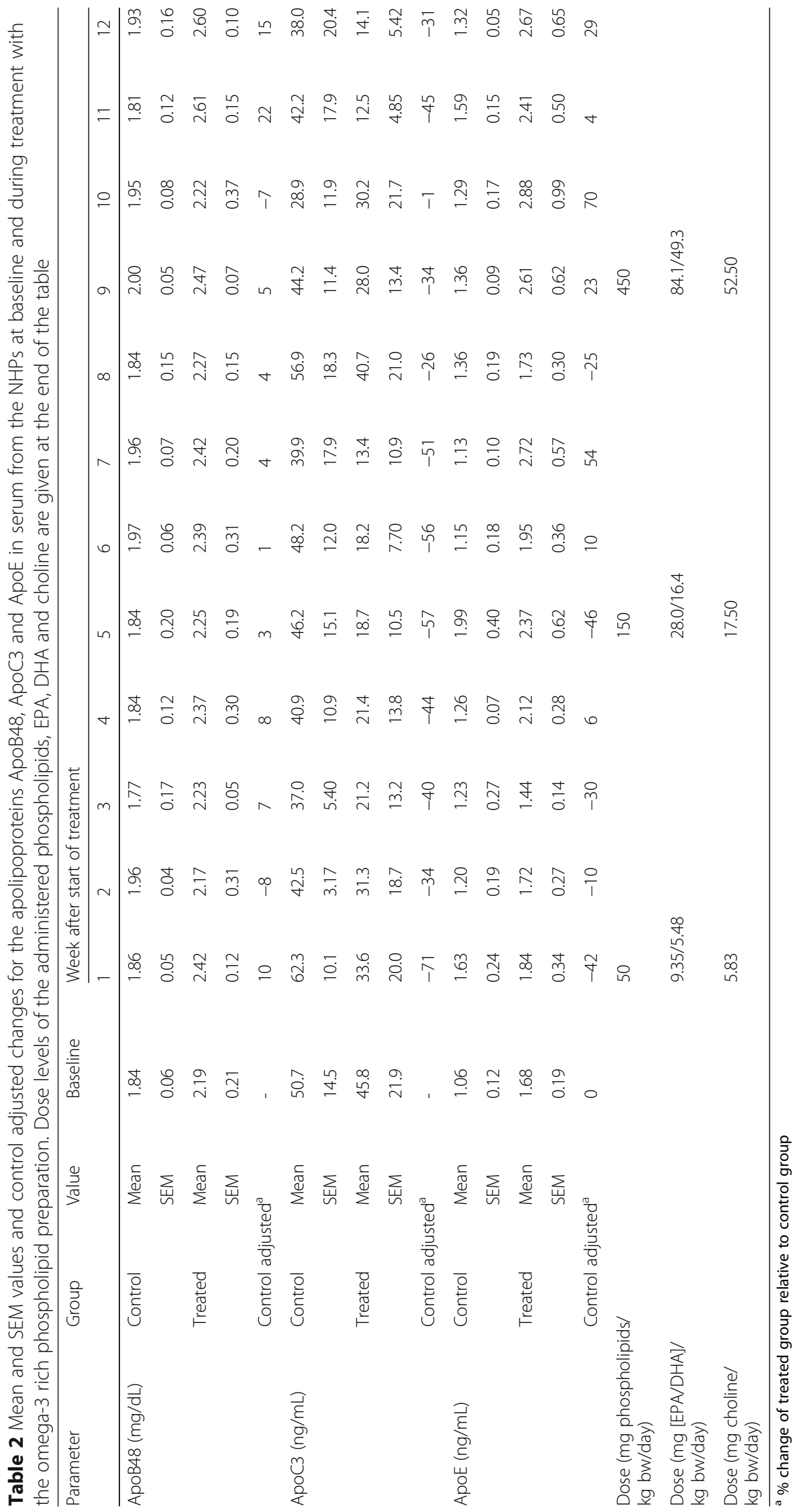




\section{Biomarkers of diabetes and inflammation}

The treatment with the purified phospholipids had no noticeable effect on the diabetes-related parameters glycated hemoglobin (HbA1c), glucose and insulin (Table 3), which is in line with findings in a metaanalysis of human studies on effects of omega-3 fatty acids on diabetes type-2 [34]. Neither was there any effect on the inflammation markers (data shown in Additional file 1), however the fact that the Creactive protein (C-rp) levels were low at baseline and throughout the study indicated that the animals had no on-going systemic inflammation, therefore this finding was as expected. Having an on-going inflammation was not one of the inclusion criteria, neither were the animals screened pre-study with respect to inflammation.

\section{Biomarkers of safety}

The results from analysis of the parameters indicative of effects on liver function, kidney function and coagulation are listed in Table 4 and show that the 12week treatment with the phospholipids up to $450 \mathrm{mg} /$ $\mathrm{kg} /$ day did not impact any of the liver and kidney biomarkers, and, furthermore, had no effects on the coagulation parameters monitored. All hematology parameters remained unchanged throughout the 12-week treatment period (data shown in Additional file 1). The bodyweight of all animals was unchanged during the 20 weeks the study lasted (data shown in Additional file 1).

\section{Discussion}

A large number of animal studies on effects of omega-3 fatty acids and other treatment regimens on elevated blood lipids have been published. The specifics of the lipid biochemistry in the various species are important to consider when studies on this topic in animal models are designed. Commonly used species in this type of research are mice, rats, dogs and pigs, but it is worth noting that none of these species has a blood lipid profile similar to the profile seen in humans, one important reason being that these species lack or have very low levels of the cholesteryl-ester transferring protein (CETP), an enzyme that transfers cholesteryl esters from HDL to LDL and VLDL [35]. Therefore these species have very low levels of LDL-c. Species that do express CETP, and therefore LDL-c levels more similar to humans, include rabbits, hamsters and non-human primates. According to Yin et al. (2012), who thoroughly reviewed the relevance of the use of various species in dyslipidemia research, the animal species most likely to predict effects of lipid-lowering treatment in dyslipidemic humans is the non-human primate and in particular the rhesus and cynomolgus strains [36]. The use of non-human primates in research should be stringently justified due to their high level of intelligence and sentience [37] but in order to extract the most predictive and relevant information from the current study we decided to use the cynomolgus monkey as our animal model. Furthermore, the animals included were suffering from naturally occurring diabetes type-2, although of such a mild type

Table 3 Mean and SEM values for the monitored diabetes-related parameters Hb1Ac, glucose and insulin in blood from the NHPs at baseline and during treatment with the omega-3 rich phospholipids. Dose levels of administered phospholipids, EPA, DHA and choline are given at the end of the table

\begin{tabular}{|c|c|c|c|c|c|c|c|c|c|}
\hline \multirow[t]{2}{*}{ Parameter } & \multirow[t]{2}{*}{ Group } & \multirow[t]{2}{*}{ Value } & \multirow[t]{2}{*}{ Baseline } & \multicolumn{6}{|c|}{ Week after start of treatment } \\
\hline & & & & 2 & 4 & 6 & 8 & 10 & 12 \\
\hline \multirow[t]{4}{*}{$\mathrm{Hb} 1 \mathrm{Ac}(\%)$} & \multirow[t]{2}{*}{ Control } & Mean & 9.07 & 8.60 & 9.00 & 9.00 & 9.37 & 9.43 & 9.80 \\
\hline & & SEM & 2.31 & 2.05 & 2.35 & 2.40 & 2.56 & 2.69 & 2.87 \\
\hline & \multirow[t]{2}{*}{ Treated } & Mean & 6.63 & 6.53 & 6.50 & 6.40 & 6.50 & 6.40 & 6.67 \\
\hline & & SEM & 1.43 & 1.64 & 1.46 & 1.37 & 1.23 & 1.48 & 1.49 \\
\hline \multirow[t]{4}{*}{ Glucose (mg(dL) } & \multirow[t]{2}{*}{ Control } & Mean & 195 & 197 & 196 & 182 & 177 & 181 & 203 \\
\hline & & SEM & 64.1 & 71.8 & 62.0 & 61.4 & 65.8 & 64.5 & 71.9 \\
\hline & \multirow[t]{2}{*}{ Treated } & Mean & 148 & 135 & 157 & 127 & 158 & 119 & 141 \\
\hline & & SEM & 41.2 & 31.7 & 38.3 & 35.5 & 30.0 & 20.0 & 32.3 \\
\hline \multirow[t]{4}{*}{ Insulin (mIU/mL) } & \multirow[t]{2}{*}{ Control } & Mean & 33.1 & 26.3 & 21.9 & 46.2 & 20.9 & 21.8 & 28.1 \\
\hline & & SEM & 5.27 & 5.32 & 4.86 & 21.28 & 5.51 & 5.61 & 10.5 \\
\hline & \multirow[t]{2}{*}{ Treated } & Mean & 66.7 & 112 & 104 & 91.6 & 115 & 74.2 & 96.7 \\
\hline & & SEM & 29.6 & 52.1 & 44.3 & 40.7 & 60.5 & 29.0 & 54.1 \\
\hline \multicolumn{4}{|c|}{ Dose (mg phospholipids/kg bw/day) } & \multicolumn{2}{|l|}{50} & \multicolumn{2}{|l|}{150} & \multicolumn{2}{|l|}{450} \\
\hline \multicolumn{4}{|c|}{ Dose (mg [EPA/DHA]/kg bw/day) } & \multicolumn{2}{|c|}{$9,35 / 5,48$} & \multicolumn{2}{|l|}{$28,1 / 16,4$} & \multicolumn{2}{|l|}{$84.2 / 49.3$} \\
\hline \multicolumn{4}{|c|}{ Dose (mg choline/kg bw/day) } & \multicolumn{2}{|l|}{5,83} & \multicolumn{2}{|l|}{17,5} & \multicolumn{2}{|l|}{52,5} \\
\hline
\end{tabular}


Table 4 Mean and SEM values for the safety parameters measured in the control and treated groups at baseline and during the 12 week treatment period. Dose levels of phospholipids, EPA, DHA and choline are given at the end of the table

\begin{tabular}{|c|c|c|c|c|c|c|}
\hline \multirow[t]{2}{*}{ Parameter } & \multirow[t]{2}{*}{ Group } & \multirow[t]{2}{*}{ Value } & \multirow[t]{2}{*}{ Baseline } & \multicolumn{3}{|c|}{ Week after start of treatment } \\
\hline & & & & 4 & 8 & 12 \\
\hline \multirow[t]{4}{*}{ Alanine transaminase $(\mathrm{ALT})(\mathrm{U} / \mathrm{L})$} & \multirow[t]{2}{*}{ Control } & Mean & 128 & 127 & 182 & 101 \\
\hline & & SEM & 59 & 54 & 103 & 32 \\
\hline & \multirow[t]{2}{*}{ Treated } & Mean & 86 & 87 & 65 & 75 \\
\hline & & SEM & 50 & 24 & 2 & 14 \\
\hline \multirow[t]{4}{*}{ Aspartate Aminotransferase (AST) (U/L) } & \multirow[t]{2}{*}{ Control } & Mean & 36 & 32 & 44 & 33 \\
\hline & & SEM & 6 & 4 & 13 & 4 \\
\hline & \multirow[t]{2}{*}{ Treated } & Mean & 32 & 27 & 30 & 42 \\
\hline & & SEM & 9 & 5 & 6 & 11 \\
\hline \multirow[t]{4}{*}{ Alkaline Phosphatase (ALP) (U/L) } & \multirow[t]{2}{*}{ Control } & Mean & 225 & 221 & 226 & 220 \\
\hline & & SEM & 37 & 40 & 46 & 56 \\
\hline & \multirow[t]{2}{*}{ Treated } & Mean & 162 & 166 & 140 & 169 \\
\hline & & SEM & 37 & 44 & 36 & 68 \\
\hline \multirow[t]{4}{*}{ Blood Urea Nitrogen (BUN) (mmol/L) } & \multirow[t]{2}{*}{ Control } & Mean & 6.69 & 6.13 & 6.46 & 6.29 \\
\hline & & SEM & 0.46 & 0.69 & 0.67 & 0.69 \\
\hline & \multirow[t]{2}{*}{ Treated } & Mean & 6.16 & 5.65 & 5.95 & 5.65 \\
\hline & & SEM & 0.04 & 0.52 & 0.63 & 0.54 \\
\hline \multirow[t]{4}{*}{ Creatinine $(\mu \mathrm{mol} / \mathrm{L})$} & \multirow[t]{2}{*}{ Control } & Mean & 62 & 64 & 63 & 61 \\
\hline & & SEM & 23 & 23 & 23 & 23 \\
\hline & \multirow[t]{2}{*}{ Treated } & Mean & 77 & 74 & 80 & 76 \\
\hline & & SEM & 5.2 & 5.6 & 5.3 & 5.4 \\
\hline \multirow[t]{4}{*}{ Uric acid $(\mu \mathrm{mol} / \mathrm{L})$} & \multirow[t]{2}{*}{ Control } & Mean & 6.07 & 4.90 & 5.37 & 6.40 \\
\hline & & SEM & 0.17 & 0.12 & 0.12 & 0.25 \\
\hline & \multirow[t]{2}{*}{ Treated } & Mean & 7.00 & 9.17 & 6.70 & 7.13 \\
\hline & & SEM & 1.04 & 2.99 & 1.17 & 1.33 \\
\hline Cystatin C (mg/L) & Control & Mean & 1.23 & 1.17 & 1.15 & 1.10 \\
\hline & & SEM & 0.21 & 0.23 & 0.22 & 0.16 \\
\hline & Treated & Mean & 1.21 & 1.23 & 1.26 & 1.24 \\
\hline & & SEM & 0.01 & 0.10 & 0.10 & 0.10 \\
\hline Prothromin time (PT) (sec) & Control & Mean & 9.90 & 9.8 & 10.5 & 10.6 \\
\hline & & SEM & 0.36 & 0.40 & 0.52 & 0.64 \\
\hline & Treated & Mean & 10.1 & 10.0 & 10.6 & 10.8 \\
\hline & & SEM & 0.29 & 0.36 & 0.32 & 0.20 \\
\hline Activated Partial Thromboplastin time (APTT) (sec) & Control & Mean & 19.3 & 19.7 & 19.1 & 18.9 \\
\hline & & SEM & 0.18 & 0.47 & 0.73 & 1.22 \\
\hline & Treated & Mean & 21.0 & 21.9 & 21.5 & 21.5 \\
\hline & & SEM & 1.93 & 1.85 & 2.18 & 2.55 \\
\hline Thrombin Time (TT) (sec) & Control & Mean & 30.5 & 29.8 & 27.9 & 26.8 \\
\hline & & SEM & 0.52 & 1.73 & 1.54 & 2.18 \\
\hline & Treated & Mean & 29.3 & 28.8 & 28.7 & 28.1 \\
\hline & & SEM & 0.92 & 2.80 & 1.91 & 1.34 \\
\hline Dose (mg phospholipids/kg bw/day) & & & & 50 & 150 & 450 \\
\hline Dose (mg [EPA/DHA]/kg bw/day) & & & & $9.35 / 5.48$ & $28.1 / 16.4$ & $84.2 / 49.3$ \\
\hline Dose (mg choline/kg bw/day) & & & & 5.83 & 17.5 & 52.5 \\
\hline
\end{tabular}


that treatment by glucose-lowering therapies was not necessary. Using animals that were hyperlipidemic because of a naturally occurring disease was considered more relevant than a model where the dyslipidemia was induced artificially, e.g., by subchronic feeding with a high fat or high sucrose diet. However, because of this special selection of animal model, the number of primates included was deliberately kept to a minimum in accordance with the 3Rs and as recommended in the Weatherall report on the use of non-human primates in research [38]. For the animals included, care and use were conducted in accordance with all applicable assessments and accreditations of the laboratory animal care (AAA$\mathrm{LAC}$ ) regulations and guidelines and the institutional animal care and use committee approved all applied procedures. Furthermore, the animals were not euthanized at the end of the 20-week in-life phase of the study but were forwarded into a further wash-out period with the intention of being used for other studies later. As a means to compensate for the low number of animals per group and increase the reliability of the results, the most important parameters were measured by more than one method where possible. This was the case for LDL and HDL as well as for triglycerides.

The main finding in the study presented here was that the purified, LC omega-3 rich phospholipid preparation extracted from krill oil reduced total circulating cholesterol, LDL-cholesterol and triglycerides and increased HDL-cholesterol when dosed over a 12 -week period to dyslipidemic non-human primates with naturally occurring diabetes type-2. The animals were given escalating doses of the test and control articles, with each dose level given daily for 4 weeks. The observed effects were mostly dose-dependent although the lowest dose, which was $50 \mathrm{mg}$ phospholipids $/ \mathrm{kg} /$ day and given during the first 4 weeks of treatment, had no detectable effect on total cholesterol and LDL-c, however an apparent increase in HDL and ApoA1 was observed. Triglyceride levels were also reduced. The lack of effect on total cholesterol and LDL-c with the lowest dose could either be due to the dose being too low or that treatment with this preparation needs to go on for longer than 4 weeks to have an effect on these parameters. The intermediate dose of $150 \mathrm{mg} / \mathrm{kg} /$ day, given during weeks 4-8, clearly reduced total cholesterol, LDL-C and triglycerides and increased HDL-c and the highest dose of $450 \mathrm{mg} / \mathrm{kg} /$ day, given during weeks 8-12 of treatment, had even more significant effects on these primary parameters and proved the potential of this preparation to modify blood levels of the cholesterols in a health-beneficial pattern. When judging these findings, however, it is important to keep the study design in mind, particularly the fact that all three doses were given to the same animals and that there was a possible accumulation effect.
Hence, the effects observed with the intermediate dose may have been influenced by the low dose and likewise, the effects of the high dose may have been influenced by the low and intermediate doses. From this it is evident that although the data indicated a dose-response relationship for most parameters, this relationship should be interpreted with some caution.

In blood, cholesterol is mostly associated with plasma lipoproteins, which allow transport around in the body at concentrations much higher than would otherwise be possible for lipophilic compounds. The specific lipoproteins LDL and HDL are built around one major apolipoprotein each so the concentration of these apolipoproteins is generally correlated with the concentrations of the associated lipoproteins, although variation in size of the lipoprotein particles can to some degree alter the correlation between concentration of apolipoprotein and the associated cholesterol [39]. In the present study, however, LDL and HDL particle size were measured and it was observed that the particles did not change their size during the course of the study. The measurements of the main apolipoproteins for LDL (ApoB100) and HDL (ApoA1) revealed that the patterns for LDL and ApoB100 were similar, and the same was the case for HDL and ApoA1. These coherent patterns strengthen the evidence that the observed reduction in total cholesterol and LDL-c and the increase in HDL-c are biologically significant.

In a review published in 2006, Balk and co-workers evaluated 21 studies on effects of fish oil and plantsource omega-3 fatty acids on serum cholesterol and other markers considered to be risk factors for development of cardiovascular disease [40]. By combining the data in the 21 studies they found clear and dose-related effects of fish-oil only on triglyceride levels while there was no effect on total cholesterol. HDL-c and LDL-c increased slightly. The data for omega-3 from plants, i.e., alpha-linolenic acid (C18:3n3), were more unclear and no conclusive evidence of effects on the serum biomarkers was seen. In a meta-analysis published in 2012 and based on 20 studies including 68680 patients, Rizos et al. concluded that LC omega-3 PUFAs are not statistically significantly associated with major cardiovascular outcomes across various patient populations [41]. This publication did not specify the source of the omega-3 s administered to the populations but given that the vast majority of omega- 3 products on the market originate from fatty fish it can be assumed that most of the subjects used fish oil. There is a lack of larger studies and meta-analyses of effects of krill oil and results from individual studies are equivocal with respect to effects on cholesterols. Bunea at al. gave Neptune Krill oil (NKO) to patients with hyperlipidemia at doses of 1-3 g/day for 90 days and observed dose-dependent effects on all main blood lipids. The highest dose of $3 \mathrm{~g} /$ day reduced total 
cholesterol by $18 \%$, LDL-c by $37 \%$ and triglycerides by $28 \%$ and at the same time increased HDL-c by as much as $55 \%$ [42]. In a recently published randomized controlled clinical trial, Lobraico and co-workers gave krill oil containing $1 \mathrm{~g}$ omega- 3 fatty acids to patients with diabetes type- 2 for 17 weeks and demonstrated that following treatment, the patients had significantly improved endothelial function and increased HDL but no effect was seen on LDL levels, neither relative to baseline nor to a control population given olive oil [43]. Berge et al. (2014), giving krill oil up to $4 \mathrm{~g}$ /day for 12 weeks to subjects with borderline high or high serum triglyceride levels did not see any significant effects on cholesterols but observed a reduction in triglycerides [44]. Interestingly, a recent randomized, cross-over study from Cicero et al. compared the effects of $500 \mathrm{mg}$ krill oil given twice a day with those of $1000 \mathrm{mg}$ omega-3 ethyl ester twice a day and found that although the ethyl esters were more efficacious than krill oil in reducing triglycerides, only krill oil was able to significantly increase HDL-c and ApoA1 levels [45]. One reason for this difference in outcome might be the baseline level of blood lipids in the studied populations because generally, the more abnormal baseline levels of blood lipids the more significant effects might be expected of the various lipidlowering treatments.

The main components of normal krill oil are around $40 \%$ phospholipids in addition to triglycerides, free fatty acids and the natural antioxidant astaxanthin [46]. The major part $(>65 \%)$ of the omega-3 fatty acids in krill oil is in the phospholipid fraction. Fish oil consists mainly of triglycerides with which the omega- 3 fatty acids are associated. This variation in omega-3 fatty acid chemistry might cause a difference in important factors mediating effects on blood lipids like distribution to tissues, distribution among the various lipoproteins in blood and effects on regulators of lipid metabolism in the liver. In addition, the main phospholipid in krill oil is phosphatidylcholine which is the main source of the essential nutrient choline in mammals. Choline has been shown to influence cholesterol metabolism and transport [47] and the administration of a combination of omega-3 fatty acids and choline could potentially cause an additive or synergistic, beneficial effect on the blood cholesterol levels. Hence, when considering pharmacological effects of LC omega- $3 \mathrm{~s}$ it is necessary to specify the source and chemical composition of the fatty acids administered. In the present study, the omega- $3 \mathrm{~s}$ were bound only in phospholipids and this is a preparation basically different from other forms of omega-3 $\mathrm{s}$ that have been investigated previously for similar indications and it should not be considered equivalent to natural krill oil.

The main conclusions from this work were based on control-corrected values, where the original measurements first were baseline-adjusted. This was done to take full value of the data obtained in the control group which was equal in size to the treated group. The control group was given the same vehicles as the treated group and is therefore expected to correct for any biological effects of the vehicles, ethanol and PEG400, as well as for effects of the frequent handling (dosing, weighing and blood sampling) of the animals during the course of the study. However, when considering the absolute values obtained during the analysis of the blood samples, the trends of reduced total cholesterol, LDL-c and triglycerides and increased HDL-c were obvious even without adjusting for the changes in the control animals but the dose-response relationships were more obvious when taking the control data into account, indicating that this could be the more relevant way to interpret the data.

The most important limitation of the current study is obviously the number of animals being included in the experiments. While a group size of 3 animals allows trends to be detected, statistical analyses are not meaningful with this low number. Therefore, the data were mainly used to assess trends in the various parameters and statistics was limited to estimating standard error of means in order to indicate the variation around the mean values.

\section{Conclusions}

This study demonstrated that long-term treatment with a novel and highly purified omega- 3 rich phospholipid preparation extracted from krill oil altered the blood lipid profiles in dyslipidemic, diabetic non-human primates markedly and in a health-beneficial manner by reducing total cholesterol, LDL-cholesterol and triglycerides while it increased HDL-cholesterol. No effects were observed on lipoprotein particle size and diabetes parameters. There were no effects on coagulation parameters, and commonly used biomarkers of liver and kidney toxicity were unchanged. This preparation may potentially be a useful therapy to normalize dyslipidemia without significant side-effects, either alone as a singleagent treatment or in combination with other therapies like statins or PCSK9 inhibitors. In addition, the known anti-inflammatory effects of the LC omega- 3 fatty acids EPA and DHA could further reduce the risk of developing atherosclerotic, cardiovascular diseases. However, further pre-clinical studies are required to elucidate the full potential and the mechanism(s) of action of this preparation and to justify its entrance into clinical trials.

\section{Methods}

Test and control articles

The test article used was a preparation of 98\% pure phospholipids, extracted from krill oil originating from 
Antarctic krill (Euphausia superba) supplied by Aker Biomarine, Oslo, Norway and formulated for oral administration by adding $12.5 \%$ poly-ethylene glycol with a MW of 400 (PEG400) and 3.5\% absolute ethanol, hence the test article contained $84 \%$ (840 $\mathrm{mg} / \mathrm{g}$ ) phospholipids. Phospholipids from krill oil are rich in omega-3 fatty acids and the final preparation contained $157 \mathrm{mg}$ EPA (C20:5n3)/g and $92 \mathrm{mg}$ DHA (C22:6n3)/g. Gaschromatography analysis detected 23 fatty acids in the end-product in addition to EPA and DHA, five of these were present with an abundance of more than $1 \%$ (10 mg/g): myristic acid (C14:0) 1.1\%, palmitic acid (C16:0) 13.2\%, oleic acid (C18:1n9) 2.1\%, cis-vaccenic acid (C18:1n11) $3.1 \%$ and stearidonic acid (C18:4n3) 1.3\%. Phosphatidylcholine comprised $90 \%$ of all phospholipids in the preparation, and the choline moiety constitutes $13 \%$ of the phosphatidylcholine molecule. Dose levels given throughout the text refer to the dose of phospholipids, i.e., a dose of $50 \mathrm{mg} / \mathrm{kg} /$ day means $50 \mathrm{mg}$ of purified phospholipids/kg body weight/day. Daily doses of EPA, DHA and choline are however specified in the tables presenting the results. The control article was composed of $84 \%$ water, $12.5 \%$ PEG400 and $3.5 \%$ ethanol and by this, both the control and treated animals received the same dose of the vehicles but for the controls, the phospholipids were substituted by water. To ease the administration, the test article was warmed to ca. $35^{\circ} \mathrm{C}$ and mixed with water just prior to dosing to make an aqueous emulsion with low viscosity. To keep consistency, the control article was treated identical to the test article. The phospholipid formulation used has been proven stable for at least 6 months.

\section{Animals}

Six type-2 diabetic and dyslipidemic cynomolgus monkeys (Macaca fascicularis) were selected for the study, after screening a total of 34 animals. Inclusion criteria were predefined and were related to diabetes parameters (HbA1c, glucose and insulin) and blood lipid levels (triglycerides, total cholesterol, LDL-c and HDL-c). The animals included were defined diabetic and hyperlipidemic with reference to normal levels in this strain of monkeys housed at Crown Biosciences in Taicang, China. The vital data and the individual screening values for the monkeys included in the study are detailed in Table 5.

The animals were housed individually in cages, in rooms with a temperature of $20-23{ }^{\circ} \mathrm{C}$, humidity 40 $70 \%$ and a $12 \mathrm{~h}$ dark/light cycle. They were fed a standard monkey diet containing crude protein $(\geq 16 \%)$, crude fat $(\geq 4 \%)$, moisture $(\leq 10 \%)$, ash $(\leq 7 \%)$, fiber $(\leq 4 \%)$, calcium $(0.8-1.2 \%)$ and phosphorus $(0.6-0.8 \%)$. The content of omega- 3 fatty acids in the diet was not measured by the supplier (Beijing Keao Xieli Feed Co. Ltd., Beijing, P.R. China) and was therefore unknown. Care and use of the animals were conducted in accordance with all applicable assessments and accreditations of the laboratory animal care (AAALAC) regulations and guidelines. Crown bioscience institutional animal care and use committee (IACUC) approved all animal procedures used in the study. All the procedures related to handling, care and treatment of the animals were performed according to the guidelines approved by AAALAC. After each handling (weighing, bleeding or dosing), the animals were observed until they were able to stand up and alert if they were anesthetized. At the time of routine monitoring, the animals were checked for any effects of the compound on their behavior such as mobility, food and water consumption, body weight gain/loss, and any other abnormal activities. Clinical abnormalities observed were recorded and reported. After completion of the study the animals were returned to the stock of diabetic monkeys held at Crown Biosciences for a recovery period and following this they were allowed to be used in other studies.

\section{Administration of test and control articles}

The control and test articles were given by gavage, $1 \mathrm{~h}$ after the first feeding of the day. The control article was

Table 5 Vital data and results from the screening of the animals included in the study. The normal range values refer to values measured in normal, non-diabetic cynomolgus monkeys housed at the laboratory where this study was conducted

\begin{tabular}{|c|c|c|c|c|c|c|c|c|c|c|c|}
\hline \multirow[t]{3}{*}{ Group } & \multirow[t]{3}{*}{ Animal ID } & \multirow[t]{3}{*}{ Sex } & \multirow{3}{*}{$\begin{array}{l}\text { Age } \\
\text { (years) }\end{array}$} & \multirow{3}{*}{$\begin{array}{l}\text { Bodyweight } \\
(\mathrm{kg})\end{array}$} & \multicolumn{7}{|c|}{ Screening parameters } \\
\hline & & & & & $\mathrm{TC}$ & LDL & $\mathrm{HDL}$ & $\mathrm{TG}$ & $\mathrm{Hb} 1 \mathrm{Ac}$ & Glucose & Insulin \\
\hline & & & & & $(\mathrm{mg} / \mathrm{dL})$ & $(\mathrm{mg} / \mathrm{dL})$ & $(\mathrm{mg} / \mathrm{dL})$ & $(\mathrm{mg} / \mathrm{dL})$ & $(\%)$ & $(\mathrm{mg} / \mathrm{dL})$ & $(\mathrm{m} / \mathrm{U} / \mathrm{L})$ \\
\hline \multirow[t]{3}{*}{ Control } & Control no. 1 & M & 14 & 9.22 & 140 & 57.0 & 57.0 & 162 & 13.8 & 261 & 9.70 \\
\hline & Control no. 2 & M & 15 & 10.0 & 103 & 48.0 & 38.0 & 55.0 & 10.2 & 234 & 22.4 \\
\hline & Control no. 3 & $\mathrm{~F}$ & 13 & 4.32 & 191 & 76.0 & 80.0 & 89.0 & 4.6 & 67 & 36.7 \\
\hline \multirow[t]{3}{*}{ Treated } & Treated no. 1 & M & 14 & 8.30 & 188 & 74.0 & 60.0 & 269 & 17.5 & 157 & 200 \\
\hline & Treated no. 2 & $\mathrm{~F}$ & 21 & 7.34 & 256 & 162 & 40.0 & 400 & 10.1 & 224 & 56.1 \\
\hline & Treated no. 3 & M & 20 & 10.8 & 128 & 49.0 & 61.0 & 50.0 & 5.90 & 109 & 51.8 \\
\hline \multicolumn{5}{|c|}{ Normal range } & $97 \pm 4$ & $35 \pm 3$ & $30-55$ & $14-88$ & $\leq 5$ & $40-75$ & $20-50$ \\
\hline
\end{tabular}


administered at the same volume $/ \mathrm{kg}$ as the test article. For the first 4 weeks, a phospholipid dose of $50 \mathrm{mg} / \mathrm{kg}$ / day was given, the next 4 weeks the dose was $150 \mathrm{mg} /$ $\mathrm{kg} /$ day and for the last 4 weeks $450 \mathrm{mg} / \mathrm{kg} /$ day. Dosing volumes were based on body weights recorded bi-weekly after overnight fasting. When converted to human equivalent dose (HED) these doses were equivalent to approximately 1, 3 and $10 \mathrm{~g} /$ day, respectively, to an adult person of $70 \mathrm{~kg}$.

The dosing was done by inserting a naso-/oral-/gastric tube into the stomach and injecting the correct volume as a bolus. The tube was then flushed with $5 \mathrm{~mL}$ lukewarm water to assure the administration of the entire volume.

Following completion of the 12-week dosing period, the animals were followed for 8 more weeks to investigate how selected parameters developed upon cessation of treatment. During these 8 weeks, neither the control nor the test article was given but blood samples were drawn bi-weekly and prepared for analysis.

\section{Blood sampling and analysis}

After overnight fasting and before dosing, blood was sampled at baseline, i.e., before starting the treatment with the control or test item, and either weekly, biweekly or every 4 weeks during the 12-week dosing period for analysis of the experimental parameters. Weekly, the following primary parameters were analyzed in blood serum by a Siemens Advia-2400 Clinical Chemical System: Total cholesterol, LDL cholesterol (LDL-c), HDL cholesterol (HDL-c), triglycerides, apolipoprotein B100 (ApoB100), apolipoprotein A1 (ApoA1), apolipoprotein B48 (ApoB48), apolipoprotein C3 (ApoC3) and apolipoprotein E (ApoE). Non-HDL cholesterol (NonHDL-c) was estimated by subtracting HDL-c from total cholesterol. Parameters analyzed bi-weekly in blood: Glycated hemoglobin (Hb1Ac, by ion-exchange HPLC), glucose (by Siemens Advia-2400), insulin (by Siemens Advia Centaur XP) and C-reactive protein (C-rp, by Siemens Advia-2400). Triglycerides and lipoproteins, including concentration and size of LDL and HDL particles, were measured bi-weekly in blood plasma by nuclear magnetic resonance (NMR) spectroscopy. The following parameters were measured bi-weekly in plasma by Luminex kits: soluble intercellular adhesion molecule-1 (sIC AM-1), soluble vascular adhesion molecule-1 (sVCAM1), P-selectin, monocyte chemotactic protein-1 (MCP1) and macrophage colony-stimulating factor (M-CSF). Fatty acids in erythrocyte membranes, including the omega-3 index [27] were also measured bi-weekly by a previously described method based on formation of fatty acid methyl esters and analysis by gas chromatography with flame ionization detection [48] (only the omega-3 index values are reported here, the timecourse of the 24 individual fatty acids analyzed is reported elsewhere). At baseline and every 4 weeks during the dosing period, just before increasing the dose to the next level, the following parameters were measured: aspartate aminotransferase (AST), alkaline phosphatase (ALT), blood urea nitrogen (BUN), creatinine, uric acid (UA), cystatin-C, prothrombin time (PT), activated prothrombin time (APTT), thrombin time (TT), white blood cell concentration (WBC, total and differential counting), red blood cell concentration (RBC), hematocrit (Hct), mean cellular volume of RBC $(\mathrm{MCV})$, mean cellular hematocrit $(\mathrm{MCH})$ and mean corpuscular hemoglobin concentration (MCHC).

Plasma sampled at baseline and at 1, 2, 4, 8, 12, 24 and $48 \mathrm{~h}$ and 7,14 and 21 days after the first dose of each dose level, and in addition at 28 days after the first dose of the highest dose level of $450 \mathrm{mg} / \mathrm{kg} /$ day, were analyzed for the determination of EPA, DPA and DHA concentrations by a liquid chromatography tandem mass-spectrometry (LC-MS/MS) method specifically developed for this purpose. This method will be published separately but in brief, plasma samples were prepared using protein precipitation followed by alkaline hydrolysis to release the fatty acids from phospholipids, triglycerides and other lipid classes to the free form. Deuterated EPA (EPA-d5) and DHA (DHA-d5) were used as internal standards. The determination of fatty acid concentrations, which were the sum of endogenous EPA, DPA and DHA and these fatty acids stemming from the administered compound, was done by MS/MS (PE Sciex API 4000) using Turbolonspray in negative ion, multiple reaction monitoring mode.

The blood samples taken during the 8 weeks after end of treatment were analyzed for the following parameters: total cholesterol, LDL-c, HDL-c, triglycerides, apoB100, ApoA1, LDL particle size as well as omega-3 index and plasma concentrations of EPA, DPA and DHA. The methods applied were the same as listed above.

In addition to the above parameters, blood samples were taken bi-weekly for analysis of the following endocannabinoids and endocannabinoid-type compounds in plasma: anandamide, 2-arachidonoylglyceride, EPA ethanolamide, DHA ethanolamide, palmitoyl ethanolamide and oleoyl ethanolamide. The results of these analyses will be published separately, together with the results of the fatty acid concentrations in erythrocyte mebranes.

\section{Data presentation and statistics}

The data tabulated for the main parameters (cholesterols, apolipoproteins and triglycerides) are firstly absolute arithmetic mean of each parameter in the control and treated group, with standard error of the mean (SEM) to indicate the variability in the groups, secondly the control adjusted changes. Control adjusted values were calculated by normalizing all values measured 
during and after treatment to the baseline values, i.e., by defining the baseline value in each animal as $100 \%$ and then calculate the change relative to baseline. The resulting mean at each time-point in the treated group is then subtracted from the mean of corresponding time-points in the control group, giving the control-adjusted change at each data-point. For diabetes and safety parameters, mean and SEM values are presented.

Given the low number of animals in each of the two groups, comparison of effects based on statistical criteria was not done. Despite the low number of animals in each group, arithmetic mean rather than median was used to describe the group changes in the measured parameters at each time-point, both for absolute values and for values normalized to baseline.

\section{Additional file}

Additional file 1: Inflamm Hematol BW. (XLSX 28 kb)

\section{Abbreviations}

ApoA1: Apolipoprotein A1; ApoB100: Apolipoprotein B100; ApoB48: Apolipoprotein B48; ApoC3: Apolipoprotein C3; ApoE: Apolipoprotein E; C-rp: C-reactive protein: DHA: Docosahexaenoic acid; DPA: Docosapentaenoic acid; EPA: Eicosapentaenoic acid; FA: Fatty acid; HbA1c: Glycated hemoglobin; HDL: High-density lipoprotein; HDL-c: High-density lipoprotein cholesterol; HMG-CoA: 3-hydroxy 3-methylglutaryl Coenzyme-A reductase; LC: Long-chain; LDL: Low-density lipoprotein; LDL-C: Lowdensity lipoprotein cholesterol; NHPs: Non-human primates; PCSK9: Proprotein convertase subtilisin/kexin type 9; VLDL: Very-low-density lipoprotein

\section{Acknowledgements}

The authors thank LipoScience Inc, NC USA for performing the lipoprotein particle analyses and OmegaQuant, LLC, SD USA for performing the analyses of fatty acids in erythrocyte membranes. We also want to thank Dr. Nils Hoem at Aker Biomarine, Lysaker Norway for reviewing the manuscript and providing useful input to it.

\section{Funding}

This study was funded by Aker Biomarine Antarctic AS.

\section{Availability of data and materials}

The datasets generated during the current study are available from the corresponding author on reasonable request.

\section{Authors' contributions}

PAH designed the study, analyzed and interpreted the data and wrote the majority of the manuscript. XLW performed the practical part of the experiments and contributed to the preparation of the manuscript. YFX designed the study, performed practical parts of the study, organized and interpreted the data and contributed to the preparation of the manuscript. All authors have read and approved the final manuscript.

\section{Competing interests}

$\mathrm{PAH}$ is an employee of Aker Biomarine Antarctic AS, Norway; XLW and YFX are employees of Crown BioSciences, Inc., P.R. China. The authors declare that they have no other competing interests.

\section{Consent for publication}

Not applicable.

\section{Ethics approval and consent to participate}

The experimental protocol was reviewed and approved by the Institutional Animal Care and Use Committee (IACUC) of Crown Bioscience, Inc., approval no. AN-1308-016-15. During the study, any change of the approved protocol was submitted as an amendment to the IACUC for approval before conducting the changed procedure. Crown Bioscience, Inc. is accredited by the Association for Assessment and Accreditation of Laboratory Animal Care (AAALAC) International.

\section{Author details}

${ }^{1}$ Aker Biomarine Antarctic AS, Oksenoyveien 10, N-1366 Lysaker, Norway. ${ }^{2}$ Crown Bioscience (Taicang) Inc., Science and Technology Park, 6 Beijing West Road, Taicang, Jiangsu Province, People's Republic of China.

Received: 6 October 2016 Accepted: 5 January 2017

Published online: 17 January 2017

\section{References}

1. Taylor F, Huffman MD, Macedo AF, Moore THM, Burke M, Davey Smith G, Ward K, Ebrahim S. Statins for the primary prevention of cardiovascular disease. Cochrane db syst rev. 2013;1:C004816.

2. Horton JD, Cohen JC, Hobbs HH. PCSK9: a convertase that coordinates LDL catabolism. J Lipid Res. 2009:50(Suppl):S172-7.

3. Hewing B, Fisher EA. Rationale for cholesteryl ester transfer protein inhibition. Curr Opin Lipidol. 2012;23:372-6.

4. Perry CM. Lomitapide: a review of its use in adults with homozygous familial hypercholesterolemia. Am J Cardiovasc Drugs. 2013;13:285-96.

5. Crooke ST, Geary RS. Clinical pharmacological properties of mipomersen (Kynamro), a second generation antisense inhibitor of apolipoprotein B. Br J Clin Pharmacol. 2013;76:269-76.

6. Harris WS, Connor WE, Alam N, Illingworth DR. Reduction of postprandial triglyceridemia in humans by dietary $\mathrm{n}-3$ fatty acids. J Lipid Res. 1988;29:1451-60.

7. Tousoulis D, Plastiras A, Siasos G, Oikonomou E, Verveniotis A, Kokkou E, Maniatis K, Gouliopoulos N, Miliou A, Paraskevopoulos T, Stefanadis C. Omega-3 PUFAs improved endothelial function and arterial stiffness with a parallel antiinflammatory effect in adults with metabolic syndrome. Atherosclerosis. 2014:232:10-6.

8. Zanetti M, Grillo A, Losurdo P, Panizon E, Mearelli F, Cattin L, Barazzoni R, Carretta R. Omega-3 polyunsaturated fatty acids: structural and functional effects on the vascular wall. Biomed Res Int. 2015;2015:791978.

9. Blok WL, Katan MB, van der Meer JW. Modulation of inflammation and cytokine production by dietary (n-3) fatty acids. J Nutr. 1996;126:1515-33.

10. Calder PC. n-3 polyunsaturated fatty acids, inflammation, and inflammatory diseases. Am J Clin Nutr. 2006;83:1505S-19.

11. Reiffel JA, McDonald A. Antiarrhythmic effects of omega-3 fatty acids. Am J Cardiol. 2006:98:50i-60.

12. Morris MC, Sacks F, Rosner B. Does fish oil lower blood pressure? A metaanalysis of controlled trials. Circulation. 1993;88:523-33.

13. Appel LJ, Miller 3rd ER, Seidler AJ, Whelton PK. Does supplementation of diet with 'fish oil' reduce blood pressure? A meta-analysis of controlled clinical trials. Arch Intern Med. 1993;153:1429-38.

14. Miller PE, Van Elswyk M, Alexander DD. Long-chain omega-3 fatty acids eicosapentaenoic acid and docosahexaenoic acid and blood pressure: a metaanalysis of randomized controlled trials. Am J Hypertens. 2014;27:885-96.

15. Harris WS. Omega-3 fatty acids and cardiovascular disease: a case for omega-3 index as a new risk factor. Pharmacol Res, 2007:55:217-23.

16. Bays H. Clinical overview of Omacor: a concentrated formulation of omega3 polyunsaturated fatty acids. Am J Cardiol. 2006:98:71i-6.

17. Bays HE, Tighe AP, Sadovsky R, Davidson MH. Prescription omega-3 fatty acids and their lipid effects: physiologic mechanisms of action and clinical implications. Expert Rev Cardiovasc Ther. 2008;6:391-409.

18. Winther B, Hoem N, Berge K, Reubsaet L. Elucidation of phosphatidylcholine composition in krill oil extracted from Euphausia superba. Lipids. 2011;46:25-36.

19. Best $\mathrm{CH}$, Huntsman ME. The effects of the components of lecithine upon deposition of fat in the liver. J Physiol. 1932;75:405-12.

20. Lee JE, Jacques PF, Dougherty L, Selhub J, Giovannucci E, Zeisel SH, Cho E. Are dietary choline and betaine intakes determinants of total homocysteine concentration? Am J Clin Nutr. 2010;91:1303-10.

21. Illingworth DR, Harris WS, Connor WE. Inhibition of low density lipoprotein synthesis by dietary omega-3 fatty acids in humans. Arteriosclerosis. 1984;4 270-5.

22. Harris WS, Ginsberg HN, Arunakul N, Shachter NS, Windsor SL, Adams M, Berglund L, Osmundsen K. Safety and efficacy of Omacor in severe hypertriglyceridemia. J Cardiovasc Risk. 1997;4:385-91. 
23. Wang C, Chung M, Lichtenstein A, Balk E, Kupelnick B, DeVine D, Lawrence A, Lau J. Effects of omega-3 fatty acids on cardiovascular disease. Evid Rep Technol Assess (Summ). 2004;94:1-8.

24. Balk EM, Adam GP, Langberg V, Halladay C, Chung M, Lin L, Robertson S, Yip A, Steele D, Smith BT, Lau J, Lichtenstein AH, Trikalinos TA. Omega-3 Fatty Acids and Cardiovascular Disease: An Updated Systematic Review. Evidence Report/Technology Assessment No 223 (Prepared by the Brown Evidence-based Practice Center under Contract No 290-2015-00002-1) AHRQ Publication No 16-E002-EF. Rockville: Agency for Healthcare Research and Quality; 2016.

25. Wang X, Wang B, Sun G, Wu J, Liu Y, Wang Y, Xiao XF. Dysglycemia and dyslipidemia models in nonhuman primates: part I. Model of naturally occurring diabetes. J Diabetes Metab. 2015;S13:010.

26. Gu H, Liu Y, Mei S, Wang B, Sun G, Wang X, Xiao Y, Staup M, Gregoire FM, Chng K, Wang YJ. Left ventricular diastolic dysfunction in nonhuman primate model of dysmetabolism and diabetes. BMC Cardiovasc Disord. 2015;15:141

27. Harris WS, Von Schacky C. The Omega-3 Index: a new risk factor for death from coronary heart disease? Prev Med. 2004:39:212-20.

28. Cladaras C, Hadzopoulou-Cladaras M, Nolte RT, Atkinson D, Zannis VI. The complete sequence and structural analysis of human apolipoprotein B-100: relationship between apoB-100 and apoB-48 forms. Embo J. 1986;5:3495-507.

29. Segrest JP, Jones MK, De Loof H, Dashti N. Structure of apolipoprotein B-100 in low density lipoproteins. J Lipid Res. 2001;42:1346-67.

30. Phillips JC, Wriggers W, Li Z, Jonas A, Schulten K. Predicting the structure of apolipoprotein A-I in reconstituted high-density lipoprotein disks. Biophys J. 1997:73:2337-46.

31. Gogonea V. Structural Insights into High Density Lipoprotein: Old Models and New Facts. Front Pharmacol. 2015;6:318.

32. Brown W, Levy Rl, Fredrickson DS. Studies of the proteins in human plasma very low density lipoproteins. J Biol Chem. 1969;244:5687-94.

33. Ginsberg HN, Brown WV. Apolipoprotein CIII: 42 Years Old and Even More Interesting. Arterioscl Throm Vas. 2011;31:471-3.

34. Hartweg J, Perera R, Montori V, Dinneen S, Neil HA, Farmer A. Omega-3 polyunsaturated fatty acids (PUFA) for type 2 diabetes mellitus. Cochrane db syst rev. 2009;1:CD003205.

35. Tsutsumi K, Hagi A, Inoue Y. The relationship between plasma high density lipoprotein cholesterol levels and cholesteryl ester transfer protein activity in six species of healthy experimental animals. Biol Pharm Bull. 2001;24:579-81.

36. Yin W, Carballo-Jane E, McLaren DG, Mendoza VH, Gagen K, Geoghagen NS, McNamara LA, Gorski JN, Eiermann GJ, Petrov A, et al. Plasma lipid profiling across species for the identification of optimal animal models of human dyslipidemia. J Lipid Res. 2012;53:51-65.

37. Tardif SD, Coleman K, Hobbs TR, Lutz C. IACUC review of nonhuman primate research. Ilar J. 2013;54:234-45.

38. Weatherall D. The use of non-human primates in research. The Royal Society 2006. https://royalsociety.org/topics-policy/publications/2006/ weatherall-report/. Accessed 7 June 2016.

39. Barter PJ, Ballantyne CM, Carmena R, Castro Cabezas M, Chapman MJ, Couture P, de Graaf J, Durrington PN, Faergeman O, Frohlich J, et al. Apo B versus cholesterol in estimating cardiovascular risk and in guiding therapy: report of the thirty-person/ten-country panel. J Intern Med. 2006;259:247-58.

40. Balk EM, Lichtenstein AH, Chung M, Kupelnick B, Chew P, Lau J. Effects of omega-3 fatty acids on serum markers of cardiovascular disease risk: a systematic review. Atherosclerosis. 2006;189:19-30.

41. Rizos EC, Ntzani EE, Bika E, Kostapanos MS, Elisaf MS. Association between omega-3 fatty acid supplementation and risk of major cardiovascular disease events: a systematic review and meta-analysis. JAMA. 2012;308:1024-33.

42. Bunea R, El Farrah K, Deutsch L. Evaluation of the effects of Neptune Krill Oil on the clinical course of hyperlipidemia. Altern Med Rev. 2004;9:420-8.

43. Lobraico JM, DiLello LC, Butler AD, Cordisco ME, Petrini JR, Ahmadi R. Effects of krill oil on endothelial function and other cardiovascular risk factors in participants with type 2 diabetes, a randomized controlled trial. BMJ Open Diabetes Res Care. 2015;3, e000107.

44. Berge K, Musa-Veloso K, Harwood M, Hoem N, Burri L. Krill oil supplementation lowers serum triglycerides without increasing low-density lipoprotein cholesterol in adults with borderline high or high triglyceride levels. Nutr Res. 2014;34:126-33.
45. Cicero AF, Rosticci M, Morbini M, Cagnati M, Grandi E, Parini A, Borghi C. Lipid-lowering and anti-inflammatory effects of omega 3 ethyl esters and krill oil: a randomized, cross-over, clinical trial. Arch Med Sci. 2016;12:507-12.

46. No authors listed. Krill oil Monograph. Altern Med Rev. 2010;15:84-6.

47. EFSA Panel on Dietetic Products, Nutrition and Allergies (NDA). Scientific Opinion on the substantiation of health claims related to choline and contribution to normal lipid metabolism (ID 3186), maintenance of normal liver function (ID 1501), contribution to normal homocysteine metabolism (ID 3090), maintenance of normal neurological function (ID 1502), contribution to normal cognitive function (ID 1502), and brain and neurological development (ID 1503) pursuant to Article 13(1) of Regulation (EC) No 1924/2006. EFSA Journal 2011;9(4):2056. [23 pp.]. doi: 10.2903/j.efsa.2011.2056. Available online: http://www.efsa.europa.eu/efsajournal.

48. Harris WS, Von Schacky C, Park Y. Standardizing methods for assessing omega-3 fatty acid biostatus. In: MacNamara RK, editor. The Omega-3 fatty acid deficiency syndrome. Nova Science Publishers Ltd; 2013. p. 385-98.

\section{Submit your next manuscript to BioMed Central and we will help you at every step:}

- We accept pre-submission inquiries

- Our selector tool helps you to find the most relevant journal

- We provide round the clock customer support

- Convenient online submission

- Thorough peer review

- Inclusion in PubMed and all major indexing services

- Maximum visibility for your research

Submit your manuscript at www.biomedcentral.com/submit
C Biomed Central 